HISTÓRIA DA FILOSOFIA

\title{
Tripartição e estrutura bipolar da alma em Platão
}

Tripartite and bipolar structure of the soul in Plato

* Marcelo Perine

\begin{abstract}
Resumo: Quando Platão trata das "afecções e as formas que ela [a alma] tem na vida humana" (República X, 612 A), ele a descreve segundo um esquema tripartite, tal como aparece também na exposição dos seus gêneros na República (IV, 437 B-441 C). No Timeu, ao tomar a via mais longa para expor a natureza da alma, Platão apresenta a Ideia da alma cósmica como uma mistura de três Ideias intermediárias procedentes de um princípio bipolar. Assim como na alma do mundo, também a alma humana possui uma estrutura tripartite hierarquizada segundo o mesmo princípio bipolar que governa a realidade. $\mathrm{O}$ artigo pretende mostrar que essas perspectivas não se contradizem, mas se completam na obra platônica.
\end{abstract}

Palavras-chave: Tripartição da alma. Estrutura bipolar. Intermediários. Mistura.

Abstract: When Plato deals with the "affections and the forms which she [the soul] takes in this present life" (Republic X, $612 \mathrm{~A}$ ), he describes it under a tripartite scheme, as it appears also in the exposure of their genres in the Republic (IV, 437 B-441 C). In the Timaeus, in undertaking the longest route to expose the nature of the soul, Plato presents the Idea of cosmic soul as a mixture of three intermediate ideas coming from a bipolar principle. Just as the soul of the world, also the human soul has a hierarchical tripartite structure using the same bipolar principle that runs the reality. The article shows that these perspectives are not contradictory but complementary in the Platonic work.

Keywords: Tripartite soul. Bipolar structure. Intermediates. Mixture.

* Professor Associado da Pontifícia Universidade Católica de São Paulo. <mperine@gmail. com>. 


\section{A composição da alma cósmica no Timeu}

To Timeu 35 AB, Platão descreve a composição da alma cósmica 1 a partir de elementos primordiais. Essa passagem constitui um ponto de partida privilegiado para estabelecer uma ponte entre as obras escritas de Platão e a sua "doutrina" intra-acadêmica, também chamada "esotérica" ou, conforme a expressão de Aristóteles, as suas "assim chamadas doutrinas não escritas" ${ }^{1}$. Sobre essa doutrina platônica da alma cósmica dispomos de um testemunho de Aristóteles no De anima (404b2127), que, segundo os adeptos da Escola Platônica de Tübingen-Milão, remete claramente os pressupostos "esotéricos" daquela passagem do Timeu ao ensinamento oral de Platão.

Vejamos o texto de Platão:

[...] entre o ser [ousias] indivisível, que é imutável, e o ser divisível que é gerado nos corpos, misturou uma terceira forma de ser feita a partir daquelas duas. E quanto à natureza do Mesmo [tautou] e do Outro [heterou], estabeleceu, de igual modo, uma outra natureza entre o indivisível e o divisível dos seus corpos. Tomando as três naturezas, misturou-as todas numa só forma e pela força harmonizou a natureza do Outro - que é difícil de misturar - com o Mesmo. Procedendo à mistura de acordo com o ser, formou uma unidade a partir das três, e depois distribuiu o todo por tantas partes quantas era conveniente distribuir, sendo cada uma delas uma mistura de Mesmo, de Outro e de ser ${ }^{3}$.

1 A expressão en tois legomenois agraphois dogmasin foi consagrada em uma passagem da Física (IV 2, 209b11-17), na qual Aristóteles refere a exposição do Timeu a conceitos que pertenceriam ao ensinamento oral de Platão. Note-se que a perspectiva hermenêutica da Escola de Tübingen-Milão aqui assumida, ao contrário de propor uma interpretação de Platão que desconsidera a obra escrita do filósofo, leva a sério a totalidade da sua obra. Nesse sentido, parece-me totalmente equivocada a posição de Maria Dulce Reis segundo a qual "antes de avaliar a possibilidade de uma nova interpretação de Platão a partir da hipótese de doutrinas não escritas, deve-se buscar entender os textos escritos por esse filósofo e realizar uma (re)leitura das concepções presentes no próprio texto platônico". Cf. REIS, M. D., Por uma nova interpretação das doutrinas escritas: a filosofia de Platão é triádica, in: Kriterion, 116 (2007), p. 379-398, aqui p. 381. A meu ver, o equívoco está em pressupor que a nova interpretação de Platão proposta pela Escola de Tübingen-Milão teria se constituído "antes" e ao arrepio de leituras e releituras exaustivas do que está contido no texto platônico e daquilo a que ele remete.

2 Sobre a discussão em torno das edições do texto, particularmente sobre a exclusão do au peri (35 A 4), cf. CORNFORD, F. M., Plato's Cosmology. The Timaeus of Plato Translated with a Running Commentary, London: Kegan Paul, 1937 [1966], p. 60, n. 1. Cf. também a posição de Brisson a esse respeito: BRISSON, L., Le même et l'autre dans la structure ontologique du Timée de Platon. Un commentaire systématique du Timée de Platon, 3ème éd. revue et corrigée, Sankt Augustin: Academia Verlag, 1998, p. 270-271.

3 PLATÃO, Timeu 35 A 1-B 3. A tradução utilizada é: PLATÃO, Timeu - Crítias, tradução do grego, introdução, notas e índices de Rodolfo Lopes, Coimbra: Centro de Estudos Clássicos e Humanísticos da Universidade de Coimbra, 2011. 
Pelo que indica o texto, a alma cósmica é o resultado final de uma mistura constituída por três elementos: (1) Ser, (2) Mesmo e (3) Outro. Esses elementos, por sua vez, procedem de três misturas anteriores: (a) a mistura entre Ser divisível e Ser indivisível, (b) a mistura entre o Mesmo divisível e o Mesmo indivisível e, finalmente, (c) a mistura entre o Outro divisível e o Outro indivisível. O processo pode ser visualizado no seguinte quadro, proposto por Cornford4:

\begin{tabular}{|l|l|l|}
\hline \multicolumn{2}{|c|}{ Mistura inicial } & \multirow{2}{*}{ Mistura final } \\
\cline { 1 - 2 } Ser indivisível & \multirow{2}{*}{ Ser intermediário } & \\
\cline { 1 - 2 } Ser divisível & \multirow{2}{*}{ Mesmo intermediário } & \multirow{2}{*}{ Alma cósmica } \\
\cline { 1 - 2 } Mesmo indivisível & \\
\cline { 1 - 2 } Mesmo divisível & Outro intermediário & \\
\cline { 1 - 2 } Outindisível & & \\
\cline { 1 - 2 } Outro divisível & &
\end{tabular}

O mesmo processo pode também ser visto no seguinte diagrama, proposto por Gaiser ${ }^{5}$ :

(IDEIAS)

Seres indivisíveis

Identidade

(ALMA)

Diversidade

O que é divisível, em devir ou corpóreo

(APARÊNCIAS)

O texto sugere que a alma cósmica encerra em si todas as propriedades opostas. É justamente isso que permite que ela se relacione com todas as coisas. Entretanto, é preciso notar, em primeiro lugar, que a oposição entre o ser estável dos seres indivisíveis, isto é, as Ideias, e o modo de ser

4 Cf. CORNFORD, F. M. Plato's Cosmology, p. 60, n. 1.

5 Cf. GAISER, K. La dottrina non scritta di Platone. Studi sulla fondazione sistematica e storica delle scienze nella scuola platonica, Presentazione di G. Reale, introduzione di H. Krämer, trad. V. Cicero, Milano: Vita e Pensiero, 1994, p. 48. 
não estável das coisas divisíveis-corpóreas, isto é, as aparências, é uma oposição de tipo ontológico. A essa oposição se contrapõe uma oposição entre idêntico e diverso, que é de tipo lógico-formal, cujo significado não coincide com o da oposição ontológica, pois Identidade e Diversidade estão presentes tanto no âmbito do indivisível como no âmbito do divisível e corpóreo. Em terceiro lugar, é preciso notar que os dois tipos de oposição, a saber, a ontológica e a lógico-formal, são determinados do mesmo modo pela oposição de Unidade e Multiplicidade. De acordo com Konrad Gaiser, esses dois tipos de oposição determinados pela oposição de Unidade e Multiplicidade permitem supor "que tudo se reconduza em última análise à única verdadeira oposição dos Princípios da filosofia platônica"6. Uma confirmação disso é a subdivisão harmônica da alma descrita logo em seguida (Timeu 35 B-36 D) ${ }^{7}$, que permite pensar que Platão tem em mente uma relação matemático-geométrica, quando descreve a composição da alma cósmica. É justamente nessa direção que a passagem do De anima de Aristóteles interpreta a descrição da alma no Timeu.

6 GAISER, K. La dottrina non scritta di Platone. Studi sulla fondazione sistematica e storica delle scienze nella scuola platonica, Presentazione di G. Reale, introduzione di H. Krämer, trad. V. Cicero, Milano: Vita e Pensiero, 1994, p. 49.

7 Eis o texto: "Então, começou a dividir do seguinte modo: em primeiro lugar, retirou uma parte do todo; em seguida, retirou outra que era o dobro da primeira; uma terceira, que corresponde a uma vez e meia a segunda e ao triplo da primeira; uma quarta, que era o dobro da segunda; uma quinta, o triplo da terceira; uma sexta, oito vezes a primeira; e uma sétima, que corresponde a vinte e sete vezes a primeira. Depois disto, preencheu os intervalos duplos e triplos, subtraindo partes da mistura inicial e colocando-as entre as outras, de tal forma que cada intervalo tivesse dois centros: um que transpõe um dos extremos e é transposto pelo outro na mesma fracção, e outro que transpõe o extremo que lhe é numericamente idêntico e também ele é transposto. Destas ligações foram gerados nos intervalos atrás referidos outros intervalos de um e meio, um e um terço e um e um oitavo. Através do intervalo de um e um oitavo, preencheu todos os de um e um terço e deixou uma parte de cada um deles, tendo este intervalo sobrante sido definido pela relação entre o número duzentos e cinquenta e seis e o número duzentos e quarenta e três. Foi deste modo que a mistura, da qual retirou aquelas partes, foi utilizada na sua plenitude. Então, cortou toda esta composição em duas partes no sentido do comprimento e, sobrepondo-as, ao fazer coincidir o centro de uma com o centro da outra (semelhante a um X) dobrou-as em círculo, juntando-as uma à outra pelo ponto oposto àquele pelo qual tinham sido ligadas, e impôs-lhes aquele movimento circular que gira no mesmo local; destes dois círculos, fez um exterior e outro interior. Então, determinou que o movimento exterior corresponderia à natureza do Mesmo, e o interior à do Outro. Fez com que o movimento do Mesmo se orientasse para a direita, girando lateralmente, e que o do Outro se orientasse para a esquerda, girando diagonalmente, e deu preeminência à órbita do Mesmo e do Semelhante, pois a ela só deixou ficar indivisa. Por outro lado, a órbita interior dividiu-a em seis partes e formou sete círculos desiguais, fazendo corresponder cada um deles a um intervalo duplo ou triplo, de tal forma que havia três tipos de intervalos. Definiu que os círculos andariam em sentido contrário uns aos outros, três dos quais com velocidade semelhante, e os outros quatro com velocidade diferente uns dos outros e dos outros três, mas movendo-se uniformemente". 


\section{O testemunho de Aristóteles sobre a interpretação de Timeu 35 A}

No primeiro livro do De anima, Aristóteles examina as concepções da alma dos pensadores precedentes. Ele afirma que alguns entenderam a alma como kinetikón, isto é, causa de movimento, outros como gnoristikòn kai aisthetikón, ou seja, causa de diferentes tipos de conhecimento. Para o segundo entendimento, Aristóteles cita antes de tudo Empédocles, depois refere-se a Platão. Eis a primeira parte do texto.

Do mesmo modo Platão, no Timeu, compõe a alma a partir dos elementos [stoicheia], pois sustenta que o semelhante é conhecido pelo semelhante e as coisas são compostas a partir dos princípios [archai], definindo similarmente nas discussões sobre a filosofia: que o próprio animal provém da ideia mesma do uno [tou henos idea] e do comprimento [mekous], largura [platous] e profundidade [bathous] primeiros [protou], e tudo o mais de modo semelhante ${ }^{8}$.

Segundo o testemunho de Aristóteles, Platão teria ensinado que o "vivente em si", ou seja, o mundo das Ideias, é constituído por uma primeira espécie de comprimento, de largura e de profundidade, e que a estrutura da alma, sendo constituída de modo análogo ao Todo, é semelhante à estrutura do mundo das Ideias. É o que parece sugerir a continuação do texto aristotélico:

Também é dito, ainda de outra maneira, que o intelecto [nous] é o uno e a ciência [episteme] é a díade: pois ela avança em direção a algo uno de um único modo; e que a opinião [doxa] é o número da superfície, e a percepção sensível [aisthesis] o do sólido; pois ele dizia que os números são as próprias formas e os princípios, embora provenientes dos elementos, e que algumas coisas são discernidas pelo intelecto, outras pela ciência, outras ainda pela opinião e outras enfim pela percepção sensível. Além disso, esses números são a forma das coisas. E como havia também a opinião de que a alma é o que pode tanto mover como conhecer, alguns então a combinaram a partir de ambos os aspectos, declarando que a alma é um número que move a si mesmo .

Aristóteles afirma que, para Platão, existe uma correspondência estrita entre (a) números (1, 2, 3, 4), (b) dimensões espaciais (unidade,

ARISTÓTELES, De anima 404b16-21 (ênfases e transliterações minhas). A tradução utilizada é: ARISTÓTELES, De anima, apresentação, tradução e notas de Maria Cecília Gomes dos Reis, São Paulo: Editora 34, ${ }^{2} 2012$. Sobre a correspondência de conteúdo entre o Peri philosophias de Aristóteles e o Peri tagathou de Platão, já sugerida por Simplício e Filopono, cf. GAISER, K., Testimonia Platonica. Le antiche testimonianze sulle dottrine non scritte di Platone, a cura di G. Reale, con la collaborazione di V. Cícero, Milano: Vita e Pensiero, 1998 (Test. Plat. 25 B).

9 ARISTÓTELES, De anima 404b21-30 (ênfases e transliterações minhas). 
comprimento, largura e profundidade, ou: unidade, linha, superfície, corpo) e (c) faculdades cognoscitivas (nous, episteme, doxa, aisthesis). Portanto, para Platão, "a mesma estrutura se apresenta em toda parte de maneira analógica: ela determina a estrutura do mundo das Ideias, o complexo da alma e a conexão de todas as coisas em geral. Assim pode-se explicar porque a alma é capaz de acolher e distinguir em si todas as coisas" ${ }^{10}$. Ainda de acordo com o testemunho de Aristóteles, deve-se pensar que essa estrutura fundamental se apresenta em graus diferentes nos três níveis, ou seja, no mundo das Ideias as dimensões se apresentam na sua forma original ideal; na alma, elas se apresentam na sua forma intermediária entre o ideal e o espacial concreto, e, finalmente, no âmbito dos corpos elas se apresentam de maneira visível e concreta ${ }^{11}$.

\section{A discussão de Gaiser com Cherniss}

$\mathrm{Na}$ discussão com a tese de Cherniss ${ }^{12}$, que atribui a Xenócrates as concepções que Aristóteles atribui a Platão nessa passagem do $D e$ anima, Konrad Gaiser, depois de uma longa análise textual da passagem, apresenta quatro grupos de fatos importantes, que demonstram que o texto aristotélico se refere a doutrinas genuinamente platônicas. Em resumo, os quatro fatos são os seguintes ${ }^{13}$ :

\subsection{O contexto do texto aristotélico}

O que demonstra que as duas proposições aristotélicas se referem a Platão é a conexão que as liga seja ao que precede, seja ao que segue. De fato, Aristóteles começa dizendo: "Platão no Timeu [...]". E, dado que ele, em seguida, declara: "definindo similarmente nas discussões sobre a filosofia [...]", então não se pode não pensar em Platão, principalmente porque não se cita nenhum novo nome e não é introduzida nenhuma outra pessoa, de modo que com a referência ao Peri philosophias ele indica apenas uma nova fonte para a mesma informação. Na segunda proposição, que começa com "Também é dito, ainda de outra maneira [...]", ele também não cita novas pessoas, mas apenas aduz o mesmo ponto de vista sob outra forma e em outro lugar, pois se aquilo ao que o "também é dito" se refere não estava contido no Peri philosophias, com

10 Cf. GAISER, K. La dottrina non scritta di Platone, p. 51.

11 Segundo ibid., p. 52, "para Platão a série das Dimensões (linha, superfície, corpo) não começa propriamente com o 'ponto' (que ele considerava ontologicamente irreal, cf. Test. Plat., 26 A), mas com o Número", que é anterior à extensão espacial-dimensional.

12 Cf. CHERNISS, H. Aristotle's Criticism of Plato and the Academy. Baltimore: Johns Hopkins Press, 1944, Appendix IX, p. 565-580.

13 Resumo aqui o que está amplamente documentado em GAISER, K., Testimonia Platonica, p. 236-247. 
toda probabilidade deriva do ensinamento de Platão, pois a referência a Xenócrates só ocorre quando ele afirma que "alguns" dos que constituíram a alma desse modo afirmaram que ela seria um número que move a si mesmo.

\subsection{O apelo ao Peri philosophias}

Os fragmentos do Peri philosophias mostram que, no segundo livro do diálogo, eram criticadas as Ideias-Números. Porém, no Peri philosophias as Ideias-Números não constituíam o objeto de um interesse específico, mas eram discutidas em vista do tema da recondução platônica de todas as coisas aos Princípios supremos. Portanto, não tem fundamento pensar que a teoria dos Números teria sido formulada por Aristóteles naquele diálogo, uma vez que no último livro do diálogo ele sustentou uma teologia cósmica totalmente diferente.

Alguns elementos levam a pensar que, no Peri philosophias, fosse tratada também a doutrina dos Pitagóricos. Com efeito, a citação de Aristóteles no De musica do Pseudo-Plutarco, sobre a harmonia dos números, é considerada um fragmento desse diálogo passível de ser interpretado pitagoricamente ${ }^{14}$. Mas, o testemunho do De anima não pode ser atribuído aos pitagóricos, porque Aristóteles nunca atribui aos pitagóricos uma "doutrina das Ideias-Números", tal como é pressuposta na passagem em questão. Pode-se até mesmo supor que Aristóteles, em seu diálogo, tenha criticado primeiro a doutrina pitagórica dos números e depois a doutrina platônica das Ideias e dos Princípios.

\subsection{As antigas interpretações da passagem aristotélica}

As mais antigas interpretações dessa passagem aristotélica já a relacionavam com doutrinas platônicas. Por exemplo, no comentário do Pseudo-Alexandre (Miguel de Éfeso) à Metafísica lê-se: "Alguns afirmam que os próprios números surgiam como Ideias para as grandezas espaciais, como a díade para a linha, a tríade para a superfície, a tétrade para o corpo; essas coisas ele [Aristóteles] as relata de Platão nos livros Perì philosophías [...]"15. Também Simplício e Filopono ${ }^{16}$, a propósito dessa passagem, embora interpretando equivocadamente a informação de que as doutrinas citadas no De anima encontram-se também no Peri tagathou, remetem indiretamente ao Peri tagathou e à doutrina oral de Platão. Enfim, há ainda uma citação, transmitida por Estobeu e extraída de Jâmblico ${ }^{17}$, que mostra que também ele considerou as proposições

14 Trata-se do fr. 25, p. 92-94 da edição de Ross.

15 PS.-ALEXANDRE (CAG 1) 777,17-19, apud GAISER, K., Testimonia Platonica, p. 242s.

16 SIMPLÍCIO 28,7-9; FILOPONO 75,34-76,1, apud GAISER, K., Testimonia Platonica, p. 243.

17 ESTOBEU, I 49,32 (I 364 Wachsmuth), apud GAISER, K., Testimonia Platonica, p. 244. 
aristotélicas como um resumo sobre a ontologia de Platão. Portanto, se no Peri philosophias Aristóteles se referisse a Xenócrates e não a Platão, dificilmente seria sustentável essa interpretação que remete as afirmações de Aristóteles a doutrinas de Platão.

\subsection{A diferença entre a doutrina de Platão e a de Xenócrates}

Segundo Cherniss, a passagem do De anima estaria em contradição com o que em outros lugares Aristóteles atribui a Platão, e concordaria com o que Aristóteles apresenta como doutrina de Xenócrates, como, por exemplo, na passagem da Metafísica XIV 3, 1090b13-1091a518, na qual Aristóteles aduziria como doutrina de Platão uma teoria da tetraktys que corresponderia ao testemunho do De anima ${ }^{19}$. No entanto, a análise mais atenta da passagem ${ }^{20}$, assim como a de Metafísica VII 11, 1036b12-1721, à qual também apela Cherniss ${ }^{22}$, revela que Platão chamava a "díade" (dyas), na qualidade de Ideia da linha, de "linha em si" (autogramme), enquanto Xenócrates a concebia mais estritamente como número e não como linha ideal. Se essa interpretação é correta, então a formulação "comprimento, largura e profundidade primeiros" [protou mekous kai

18 Dessa longa passagem o trecho que interessa é: "Os que afirmam a existência de Ideias evitam essa dificuldade. Com efeito, eles derivam as grandezas da matéria e do número, os comprimentos da díade, as superfícies da tríade e os sólidos da tétrade (ou ainda de outros números, pois isso não tem importância. Mas essas grandezas são Ideias? E se não são, qual será o seu modo de ser? Na realidade, não terão nenhuma utilidade, assim como não a têm os entes matemáticos. E mais, a elas não se poderá aplicar nenhum teorema matemático, a não ser que se queira transformar as matemáticas e inventar uma outra. Com efeito, não é difícil assumir uma hipótese qualquer e depois tirar dela uma longa série de considerações e conseqüências. Estes, portanto, erram fundindo desse modo os entes matemáticos com as Ideias. Ao invés, os que por primeiro afirmaram a existência de dois tipos de números: o número ideal e o número matemático, não disseram - nem poderiam dizer - de que modo existe o número matemático e de que deriva. De fato, fazem dele um intermediário entre o número ideal e o número sensível. Ora, se ele deriva do grande e do pequeno, deverá coincidir com o número ideal; as grandezas derivam de outro tipo de grande e pequeno. Se, ao contrário, se introduz outro elemento, então teremos uma multiplicidade de princípios. Esse o princípio formal de cada um dos dois tipos de números fosse o Um, este seria algo comum aos dois casos. Então seria preciso investigar como o Um pode ser causa dessas múltiplas coisas, tanto mais que - segundo aquele filósofo - o número só pode gerar-se do Um e da díade indefinida" (1090b20-1091a5). A tradução utilizada é: ARISTÓTELES, Metafísica, ensaio introdutório, texto grego com tradução e comentário de Giovanni Reale. Texto grego com tradução ao lado, tradução de M. Perine, São Paulo: Edições Loyola, Vol. II, ${ }^{3} 2013$.

19 Cf. CHERNISS, H. Aristotle's Criticism of Plato and the Academy, p. 569s.

20 Cf. GAISER, K. Testimonia Platonica, p. 213-227.

${ }^{21}$ Eis a passagem: "Por isso eles reduzem tudo aos números, e dizem que a noção de linha se reduz à da díade. Alguns dos filósofos defensores das Ideias afirmam que a díade é a linha em si: outros, ao contrário, afirmam que a díade é a Forma da linha, porque em alguns casos existe identidade entre Forma e aquilo de que a Forma é forma como, por exemplo, no caso da díade e da Forma da díade, enquanto no caso da linha não existe".

22 Cf. CHERNISS, H. Aristotle's Criticism of Plato and the Academy, p. 567s. 
platous kai bathous] na passagem do De anima refere-se a Platão e não a Xenócrates.

No De anima, Aristóteles não ignora a definição de Xenócrates, segundo a qual "a alma é o número que move a si mesmo". Entretanto, para Platão a alma não era um número, mas uma figura numericamente estruturada com extensão espacial. Aristóteles a interpreta exatamente desse modo, quando diz que, segundo Platão, no Timeu, a alma seria extensa de modo circular $^{23}$. Ora, parece claro que a teoria platônica está claramente adequada à afirmação de que as quatro faculdades cognoscitivas da alma são iguais aos quatro primeiros números. Ademais, como sustenta Gaiser,

também a primeira proposição do resumo aristotélico (404b18-21) conduz à concepção platônica da alma estendida espacialmente. Se, de fato, o cosmo das Ideias consiste de números, então ‘o outro' ao qual também a alma pertence, ou não é mais um número ou é outra espécie de número. Nenhum das duas alternativas coincide com a doutrina de Xenócrates ${ }^{24}$.

Outros testemunhos de Aristóteles, extraídos da Metafísica, ajudam a compreender melhor o significado ontológico atribuído por Platão à série das dimensões, embora nessas passagens Platão não seja nomeado explicitamente ${ }^{25}$. Entretanto, pelo que se pode extrair dos comentadores antigos, particularmente de Simplício, no comentário à Física, e de Alexandre de Afrodísia, no comentário à Metafísica, parece ter sido suficientemente claro desde a antiguidade que as referências aristotélicas ao método ontológico-dimensional e, portanto, à correspondência entre a série dimensional e a estrutura do ser, remetiam a um argumento genuinamente platônico ${ }^{26}$.

${ }^{23}$ Cf. ARISTÓTELES, De anima 406b25-407b12. Dessa longa passagem cito apenas o início (406b25-407a2): "Da mesma maneira também no Timeu explica em termos físicos que a alma move o corpo, pois é por mover-se e por estar entrelaçada ao corpo que ela também move. Como a alma é constituída a partir e repartida de acordo com os números harmônicos, a fim de que tenha percepção sensível inata da harmonia e que o universo se mova por locomoções consoantes, o demiurgo curvou a reta em círculo e, tendo extraído do uno dois círculos tangentes em dois pontos, de novo tornou a dividir um deles em sete círculos, como se as revoluções do céu fossem os movimentos da alma".

24 Cf. GAISER, K. Testimonia Platonica, p. 247.

25 Os testemunhos aristotélicos mais importantes são Metafísica I 9, 992a10-b18; XIII 9 , 1085a7-24; VII 2, 1028b16-32; XIV 3-4, 1090b5-1091a29; XIV 2, 1089a31-b15; V 11, 1018b371019a4; V 8, 1017b17-21, e V 6, 1016b24-1017a3, recolhidos por GAISER, K., Testimonia Platonica, 26a, 27a, 28a, 28b, 29, 33a, 33b e 35a, respectivamente.

26 A importância do comentário de Simplício está em afirmar que o método ontológicodimensional tinha sido explicado na transcrição de Aristóteles e de outros discípulos do Peri tagathou de Platão (cf. Test. Plat., 23B). No comentário à Metafísica (I 6, 987b33), Alexandre interpreta a difícil passagem sobre a função do segundo Princípio platônico na produção dos números, com uma referência explícita ao Peri tagathou platônico (cf. Test. Plat., 23B). 
Essa convicção é reforçada pelo recurso a diversas passagens dos diálogos, que revelam a centralidade dessa questão no pensamento de Platão. No texto do Timeu do qual partimos, a série dimensional é decisiva para a compreensão tanto da estrutura da alma cósmica como da sua relação com o corpo do mundo e da teoria física dos átomos. Em Leis X, 893 E-894 A, a série dimensional tem importância para o significado ontológico da descrição do movimento (genesis) ${ }^{27}$. O modelo estrutural da série dimensional também aparece na longa exposição do lugar que o sistema das ciências matemáticas (aritmética, geometria, estereometria, astronomia e harmonia) ocupa na formação do filósofo, em República VII, 522 C-529 C, como preparação para a formação dialética ${ }^{28}$. Em Leis VII, 819 C-820 C, ao tratar dos níveis de aprendizado das ciências matemáticas, o conhecimento da estrutura dimensional é decisivo para as relações de comensurabilidade e incomensurabilidade ${ }^{29}$. No excurso central do Político sobre a exatidão em si (283 B-285 C), a referência às duas espécies da arte de medir comporta uma clara relação com a questão do modelo matemático da dimensionalidade ${ }^{30}$, do mesmo modo que teria ocorrido na discussão de Teeteto com o homônimo de Sócrates

27 Dessa longa passagem transcrevo apenas uma parte (894 A): "O problema consiste agora em saber em que condições se verifica a gênese. Evidentemente, quando certo elemento estendendo-se torna-se bidimensional e, na transformação imediatamente sucessiva, torna-se finalmente tridimensional e com isso perceptível a quem é dotado de sentidos". A tradução utilizada é de Roberto Radici in: PLATONE, Tutti gli scritti, a cura di Giovanni Reale, Milano: Rusconi, ${ }^{2} 1991$.

28 Dessa longa argumentação cito apenas um trecho do final (529 B): "Parece-me não-vulgar, disse eu, o conceito que tens do estudos das coisas lá do alto... Se alguém, olhando para cima, examinar os ornamentos coloridos do teto e apreender algo sobre eles, tu podes bem vir a pensar que ele os contemplou com a inteligência e não com os olhos. Talvez estejas pensando bem e eu esteja sendo ingênuo... É que, de minha parte, não posso pensar que o outro aprendizado e não o que trata do ser e do invisível faça a alma contemplar as coisas do alto" (ênfase minha). A tradução utilizada é: PLATÃO, A República, tradução de Anna Lia Amaral de Almeida Prado, revisão técnica e introdução de Roberto Bolzani Filho, São Paulo: Martins Fontes, 2006.

29 Transcrevo apenas o início dessa longa citação: "Desse modo os mestres, adaptando em forma de jogo os exercícios da matemática elementar, ajudam os seus alunos a dividir em falanges um exército ou a dirigi-lo numa expedição, e também em vista da habilidade na administração da casa. Mas, acima de tudo, esses jogos tornam os homens mais capazes de cuidar de si mesmos e também intelectualmente mais atentos. Ademais, ao ensinar a medir as realidades que têm comprimento, largura e profundidade eles libertam daquela particular forma de ignorância, absurda e incapacitante que é congênita em cada homem" (819 CD).

30 Cito apenas a passagem mais expressiva dessa longa citação: "Evidentemente, para dividir a arte de medir da maneira que falamos teríamos que distinguir apenas duas partes: de um lado colocaríamos todas as artes para as quais o número, os comprimentos, as profundidades, larguras e espessuras se medem por seus opostos, e de outro, todas aquelas que se referem à justa medida, a tudo aquilo que é conveniente, oportuno e devido, a tudo que conserva o meio entre dois extremos" (284 E). A tradução utilizada é de Jorge Paleikat e João Cruz Costa: PLATÃO, Diálogos. O Banquete - Fédon - Sofista - Político, São Paulo: Abril Cultural, 1972. 
referida no Teeteto (147 D-148 B $)^{31}$ sobre a comensurabilidade linear, de superfície e corpórea ${ }^{32}$.

Esse conjunto de referências diretas e indiretas indica que o testemunho de Aristóteles no De anima capta adequadamente o pensamento de Platão sobre a estrutura da alma cósmica no Timeu e, portanto, traduz de maneira fidedigna o pensamento de Platão a respeito da composição e da estrutura da alma.

\section{Considerações finais}

A quádrupla articulação das faculdades cognoscitivas da alma (nous, episteme, doxa e aisthesis), correspondendo, respectivamente, ao uno, à díade, à superfície e ao sólido, à qual se refere o testemunho aristotélico do $D$ e anima ${ }^{33}$, liga-se à conhecida diferenciação platônica das "partes da alma" em racional, irascível e concupiscível. Segundo o Timeu, só a parte racional (logistikon) é divina e imortal, enquanto a irascível (thymikon) e a concupiscível (epithymetikon) são mortais como o corpo ${ }^{34}$.

Contudo, não parece haver contradição entre a quadripartição das funções cognoscitivas e a tripartição da alma. Com efeito, a hierarquia das funções cognoscitivas da alma se estabelece a partir da dupla articulação da polaridade de peras e apeíron ou de Uno e Múltiplo ou, ainda, de Mesmo/Idêntico e Outro/Diverso. A alma conhece o idêntico e o diverso em todas as coisas, porque ela os possui em si mesma: ao primeiro se referem nous e episteme, ao segundo se referem doxa e aisthesis. Essa

31 “Teeteto: Agora, Sócrates, ficou muito fácil a questão. Quer parecer-me que é igualzinha à que nos ocorreu recentemente, numa discussão entre mim e este teu homônimo. - Sócrates: Qual foi a questão, Teeteto? - Teeteto: A respeito de algumas potências, Teodoro, aqui presente, mostrou que a de três pés e a de cinco, como comprimento não são comensuráveis com a de um pé. E assim foi estudando uma após a outra, até a dezessete pés. Não sei por que parou aí. Ocorreu-nos, então, já que é infinito o número dessas potências, tentar reuni-las numa única, que serviria para designar todas" (147 DE). A tradução é de Carlos Alberto Nunes in: PLATÃO, Diálogos. Teeteto - Crátilo, Belém: Editora UFPA, 2001.

32 Cf. GAISER, K., Testimonia Platonica, p. 107-109. Gaiser afirma que pertencem a esse mesmo contexto também as seguintes passagens dos diálogos: Epínomis $991 \mathrm{E}$; Sofista $235 \mathrm{DE}$; Leis V, 747 A, X, 896 D; 904 CD; Menon 75 B-76 E; Protágoras 356 E-357 A; Cármides 165 E-166 B e Górgias 451 AC.

${ }^{33}$ Cf. o texto citado acima, na nota 9.

34 " $E$ ele mesmo se tornou demiurgo dos seres divinos, enquanto que atribuiu o encargo de fabricar os mortais àqueles que tinham sido gerados por si. Estes, imitando-o, depois de terem recebido o princípio imortal da alma, tornearam para ele um corpo mortal a que deram como veículo todo o corpo e nele construíram uma outra forma de alma, mortal, que contém em si mesma impressões terríveis e inevitáveis: primeiro, o prazer, o maior engodo do mal; em seguida, as dores, que fogem do bem; e ainda a audácia e o temor, dois conselheiros insensatos; a paixão, difícil de apaziguar, e a esperança, que induz em erro. Tendo misturado estas paixões juntamente com a sensação irracional e com o desejo amoroso que tudo empreende, constituíram a espécie mortal submetida à Necessidade" (Timeu 69 CD). 
estrutura bipolar não contradiz a tripartição da alma em racional, irascível e concupiscível, porque, segundo Gaiser, "na tripartição, Platão concebe o membro intermediário (a parte irascível da alma) como ambivalente: também aqui o intermediário unifica em si a tensão entre as oposições" 35 .

Também a oposição entre pensamento e desejo passional, procedente da tripartição da alma, funda-se na bipolaridade de Uno/Mesmo/limite (peras) e Díade/Outro/extensão indeterminada (apeiron). Com efeito, segundo Gaiser,

no âmbito do 'irascível', as diversas, múltiplas e indeterminadas forças do desejo passional devem ser equilibradas segundo a norma estabelecida pelo pensamento - assim como uma figura irregular pode ser transformada em regular, a partir do peras linear, por meio da busca do meio geométrico [...] no particular como no geral parece dominar o mesmo contraste, redutível à oposição dos Princípios, entre a epithymia ligada ao corpo e o logos (nous) que se remete às Ideias ${ }^{36}$.

O texto do Timeu que acabei de citar fala da ação simultânea das três partes da alma, pondo a parte irascível a serviço da racional contra a parte impulsiva. O laborioso equilíbrio das três partes da alma, com a submissão do epithymetikon e do thymoeides à medida imposta pelo logistikon, é, justamente, o que define a "virtude" (arete), isto é, o que é bom e belo.

Ora, segundo o Timeu, "Tudo o que é bom é belo, e o que é belo não é assimétrico; estabeleçamos que um ser vivo, para ter estes atributos, terá que ser simétrico" (87 C). Essa simetria em que consiste a virtude confirma a hipótese sobre a qual se desenvolveu a presente reflexão, a saber, a de que não há contradição, mas complementaridade entre as duas perspectivas da compreensão platônica das "afecções e as formas que ela [a alma] tem na vida humana" (República X, $612 \mathrm{~A}$ ): a da estrutura tripartite da alma, amplamente exposta nos escritos,

35 Cf. GAISER, K., La dottrina non scritta di Platone, p. 69. O texto do Timeu ilustra perfeitamente isso: "Por este motivo, temendo conspurcar a parte divina, o que não era de todo inevitável, estabeleceram a parte mortal numa outra morada do corpo, separada daquela, e construíram um istmo e um limite entre a cabeça e o peito, ao estabelecerem no meio deles o pescoço, para que fosse um separador. No peito, também chamado tórax, sediaram a parte mortal da alma. Visto que uma parte dela é, por natureza, mais forte e outra mais fraca, construíram uma divisória na cavidade do tórax, como se delimitam os aposentos das mulheres separados dos homens. Entre elas puseram o diafragma a servir de barreira. Assim, estabeleceram a parte da alma que participa da coragem e do fervor, que é adepta da vitória, mais perto da cabeça, entre o diafragma e o pescoço, para que escutasse a razão e, em conjunto com ela, refreasse pela força a espécie dos desejos, sempre que estes não quisessem de modo algum obedecer prontamente às ordens e aos decretos da cidadela do alto" (69 D-70 A).

36 Cf. GAISER, K., La dottrina non scritta di Platone, p. 69. 
particularmente na República ${ }^{37}$, e a da polaridade dos princípios do uno e da díade, fartamente documentada pela tradição indireta, a começar por Aristóteles.

Nada mais adequado, para concluir esta breve reflexão, que procurou evidenciar a complementaridade das duas tradições nas quais se encontra todo Platão, do que o comentário do grande platonista H.-G. Gadamer, que não se reporta aos cânones da Escola de Tübingen-Milão, sobre uma das afirmações conclusivas de Sócrates no Filebo ${ }^{38}$ :

A potência do bem se manifesta na figura (na natureza) do belo. O belo, enquanto síntese de aspecto externo e atitude interior (arete), de corporeidade e espiritualidade, não é algo diferente do bem, mas o próprio bem enquanto dizível e visível. A medida e a proporção são as determinações fundamentais do belo [...]. Elas, contudo, são também a força do bem [...]. Enquanto medida vinculante, o bem é algo que influi sobre o ser a partir de fora. Mas, enquanto imanente no ente, ele constitui a sua natureza; o ente é determinado pelo perfeito acordo de uma massa mensurada em si mesma: pela simetria. Justamente isso é a beleza: uma figura unificada em si mesma. A unificação do bem apresenta-se, portanto, como organização do belo ${ }^{39}$.

\section{Endereço postal:}

Marcelo Perine

Rua Itacolomi 258, apto. 11 - Bairro Higienópolis

01239-020 São Paulo, SP, Brasil

Recebimento: 01/03/2014

Aceite: 15/05/2014

37 Para uma exposição clara e didática da doutrina da tripartição da alma na República, cf. REIS, M. D., Psicologia, ética e política. A tripartição da psykhé na República de Platão, São Paulo: Edições Loyola, 2009.

${ }^{38}$ Eis o texto do Filebo: "Bem, se não somos capazes de capturar o bem com uma única forma, vamos apreendê-lo com três — beleza, proporção e verdade. E afirmaremos que, na suposição de serem os três apenas um, não estaríamos errados em responsabilizá-lo por tudo o que há na mistura, uma vez que, sendo ele bom, torna também boa a própria mistura" (65 A). A tradução utilizada é: PLATÃO, Filebo, tradução, apresentação e notas de Fernando Muniz, São Paulo - Rio de Janeiro: Edições Loyola - Editora PUC Rio, 2012. Sobre as relações de Gadamer com a Escola de Tübingen-Milão, cf. PERINE, M., Platão não estava doente, São Paulo: Edições Loyola, 2014, p. 173-189.

39 Cf. GADAMER, H.-G., Etica dialettica di Platone. Interpretazioni fenomenologiche del Filebo, in: Studi platonici I, trad. G. Moretto, Genova: Marietti, 1983, p. 174s. 